\title{
Personalised Medicine for Asthma and Chronic Obstructive Pulmonary Disease
}

\author{
Liam G. Heaney Lorcan P.A. McGarvey \\ Centre for Experimental Medicine, School of Medicine, Dentistry and Biomedical Sciences, Queens University \\ Belfast, Belfast, UK
}

\section{Key Words}

Personalised medicine - Precision medicine - Asthma .

Chronic obstructive pulmonary disease $\cdot$ Co-morbidity

\begin{abstract}
Asthma and chronic obstructive pulmonary disease (COPD) are prevalent conditions, and despite recent advances and multiple available therapies and interventions, there remains a significant unmet clinical need. In recent years, it has become clear that there is both significant heterogeneity within each of these conditions and additionally significant overlap in many of the clinical and inflammatory features. In parallel, useful clinical and immunological biomarkers which inform about prognosis and response to therapy have emerged in both asthma and COPD. These biomarkers will allow both better targeting of existing treatments and the identification of those patients who will respond to novel therapies which are now becoming available. Biomarkers will also facilitate the identification of novel therapeutic targets for future development. Delivery of precision medicine in airways disease is now feasible and is a core component of a personalised healthcare delivery in asthma and COPD.
\end{abstract}

(c) 2017 S. Karger AG, Basel

\section{Introduction}

Asthma is a clinical syndrome characterised by variable symptoms of wheeze, breathlessness, chest tightness and cough in association with bronchial hyperresponsiveness and reversible airflow obstruction [1]. Chronic obstructive pulmonary disease (COPD) is similarly characterised by symptoms of wheeze, breathlessness, chest tightness and cough which is usually productive and is associated with fixed airflow limitation, a feature which is included in most definitions [2]. In addition to chronic symptoms, both asthma and COPD are also associated with a tendency to deteriorate in an abrupt or sub-acute manner. These events are usually referred to as "exacer-

Previous articles in this series: 1 . Lange $C$, Siddiqui S: State-of-theArt Series on Precision Medicine in Respiratory Diseases. Respiration 2016;92:197-198. 2. Salzer HJF, Wassilew N, Köhler N, Olaru ID, Günther G, Herzmann C, Kalsdorf B, Sanchez-Carballo-P, Terhalle E, Rolling T, Lange C, Heyckendorf J: Personalized Medicine for Chronic Respiratory Infectious Diseases: Tuberculosis, Nontuberculous Mycobacterial Pulmonary Diseases, and Chronic Pulmonary Aspergillosis. Respiration 2016;92:199-214. 3. Sharma J, Shum E, Chau V, Paucar D, Cheng H, Halmos B: The Evolving Role of Biomarkers in Personalized Lung Cancer Therapy. Respiration 2017;93:1-14.

\section{KARGER}

(C) 2017 S. Karger AG, Basel 
bations" or "attacks" which are serious events - they can be fatal but at the very least have a major impact on patients' quality of life and considerable health economic consequences globally $[3,4]$.

There remains significant unmet need in both asthma and COPD. Up to $20 \%$ of patients with asthma do not achieve an acceptable level of control, despite being prescribed high-dose anti-inflammatory and bronchodilator therapy, and are referred to as having "difficult-to-treat asthma" or "difficult asthma" $[1,5]$. In COPD, even between exacerbations when patients are considered relatively stable, symptoms are still prevalent and problematic. In a pan-European study of COPD patients with severe disease $\left(\mathrm{FEV}_{1}<50 \%\right.$ predicted), over $90 \%$ reported some degree of symptoms on a daily basis [6]. While breathlessness was most typical, cough and sputum were also particularly bothersome [7]. An increased awareness of the impact of cough on the health status of patients with COPD [8] is recognised, and treatments directed at controlling this symptom are really needed [9].

The development of patient-reported outcome instruments, such as the COPD Assessment Test [10] and the EXACT [11] patient-reported outcome tools, has helped capture the range of symptoms and healthcare issues that need to be eased with treatment. Furthermore, the current GOLD recommendation to categorise patients based not just on lung function severity but on exacerbation risk and symptomatology helps to move away from a rather one-dimensional and outdated view of COPD as solely a disease of fixed airflow limitation and towards the idea of one with distinct disease phenotypes which need treatment options targeted in a more precise manner [2].

\section{Understanding the Clinical Problem - A Personal Issue}

Understanding the clinical problem is a core component of the personalised management of any condition. In patients with difficult-to-control asthma, after detailed systematic evaluation, a coexistent problem is often identified [12, 13], either alone (misdiagnosis) or together with mild/moderate asthma, and when this is effectively managed, symptoms can be controlled. It has also become clear that co-morbid disease is an important component of patients with COPD $[2,14]$, and optimising any co-morbid condition where this is possible is essential to gain a level of disease control. Physical deconditioning and co-morbid conditions are unlikely to respond to more treatment for airflow limitation, and clinical assess- ment must be multidimensional, including awareness of the role of extra-pulmonary factors in the overall clinical problem.

A recent and attractive concept has been that of considering airways disease in terms of so-called "treatable traits" which can be identified and potentially addressed $[15,16]$. This includes addressing extra-pulmonary factors which can improve the clinical situation but additionally breaks airways disease into elements which can be individually assessed and targeted. This deconstructs airways disease into component parts including airways inflammation, cough reflex hypersensitivity, airway structural damage and injury and bronchial hyperresponsiveness. It seems reasonable, therefore, that assessing and targeting these components at an individual level may inform the clinician how treatments may be used in a more personal manner. Some of these traits are currently more "treatable" than others, e.g., eosinophilic airways inflammation is easily modifiable, whereas cough reflex hypersensitivity has traditionally had more limited therapeutic options, although this is changing [17]. The other likely benefit of this type of approach is the avoidance of progressive escalation of treatment past the point of any reasonable expectation of therapeutic benefit, which is particularly relevant to the use of corticosteroids.

Inherent in this type of approach is challenging traditional dichotomous labels, such as asthma and COPD, and the use of a "one size fits all" treatment approach which is typified in current asthma and COPD treatment guidelines. In patients with persistent symptomatic asthma, there is often a progressive escalation of treatment, particularly with corticosteroid treatment, in an attempt to achieve asthma control. Indeed, the current definition of severe asthma mandates escalation to high-dose treatment (high-dose inhaled corticosteroids [ICS] plus second controller for the previous year or systemic corticosteroids $\geq 50 \%$ of the previous year), which either maintains asthma control or fails to achieve control [18]. Uncontrolled asthma is defined as persisting asthma symptoms, frequent severe exacerbations requiring at least 2 bursts of systemic corticosteroids (or a hospitalisation) in the previous year or persistent airflow limitation [18]. Controlled asthma that worsens on tapering of highdose corticosteroid treatment or use of additional biological therapy also fits into the category of severe disease. It is important to stress that a diagnosis of severe refractory asthma is applied only after detailed systematic multidisciplinary assessment for patients with asthma in whom alternative diagnoses have been excluded, adherence to treatment has been checked, co-morbidities have 
been treated and trigger factors have been removed (where this is possible). With the advent of the multiple new therapeutic options for severe asthma over the next few years (discussed below), it is more critical than ever to get the diagnosis and these core basic issues correct to avoid inappropriate targeting of these novel and potentially expensive therapies.

Similarly, in COPD, while ICS (in combination with long-acting bronchodilators) have formed a cornerstone of maintenance therapy for moderate and severe disease for almost 20 years, their widespread use particularly at high doses has undoubtedly been associated with adverse events [19]. Despite the overwhelming evidence that inhaled steroids reduce COPD exacerbations, chief amongst the concerns has been the increased risk of non-fatal pneumonia in some patients [20]. Recent evidence suggests that health status, symptom control and exacerbation prevention can be achieved with non-corticosteroidcontaining therapy even in those with moderate and severe disease [21]. Clearly, not all COPD patients need ICS therapy, and as some may even come to harm, identifying which patients should receive ICS is a critical issue. This will be discussed in greater detail below.

We have known for over 50 years that patients with asthma and sputum eosinophilia responded to steroid treatment, which was elegantly demonstrated by Dr Harry Morrow Brown after a negative clinical trial of corticosteroids in "all-comers" with asthma [22]. Despite this initial foray into personalised medicine, it has taken us many years to consider moving away from using excessive doses of steroids in patients with airways disease.

In addition to excessive use of inhaled steroid treatment in airways disease, there is also the challenge of nonadherence to maintenance inhaled treatment by subjects who would respond well to treatment. This is a further example of where a personalised approach is critical in addressing the clinical problem. At a simple level, nonadherence can be non-intentional, where patients want to take treatment but are prevented by barriers beyond their control, such as poor recall of instruction, low comprehension, dyspraxia or poor coordination, forgetfulness or simply because they cannot afford the treatment. This is very different from intentional non-adherence where a patient decides not to take treatment due to medication beliefs (often false), denial, secondary gain or disease beliefs. A "one size fits all" strategy is bound to fail patients given the complexity and breadth of this clinical problem. In patients presenting with difficult asthma, non-adherence is prevalent $[23,24]$ and is poorly identified in routine clinical practice, leading to poor healthcare outcome

Personalised Medicine for Asthma and COPD and death. It also leads to patients being inappropriately labelled as having "refractory" disease, with the potential for inappropriate escalation to systemic corticosteroids or biological therapies.

Recent "biomarker-based" assessments of corticosteroid response in severe asthma may identify patients who should achieve good asthma control with better adherence to standard treatment [25]. The advent of new "smart inhaler" technologies allied with these biomarker-based assessments will allow the issue of non-adherence to be identified and managed in the clinic. In COPD, non-adherence is also sub-optimal. As with asthma, this is multifactorial and includes failure to collect prescriptions of medication [26] and poor inhaler technique [27]. The nature and extent of non-adherence in patients discharged from hospital after a COPD exacerbation have recently been addressed in a study by Sulaiman et al. [28]. Using an acoustic based device built into a salmeterol/fluticasone inhaler which quantified how well and how often patients took medication they found that only $7 \%$ achieved more than $80 \%$ adherence. Not surprisingly, older patients with more severely impaired lung function and cognitive impairment were most likely to exhibit poor adherence and make frequent errors in inhaler technique.

A key challenge in both asthma and COPD remains how to manage non-adherence effectively in this patient group [29], but the starting point is identifying that nonadherence is the clinical problem in a patient who should respond well to inhaled steroid treatment. It is also likely that novel monitoring technologies with "real-time" user reminders and technique feedback will become available and allow a new series of personalised approaches with this substantial problem.

\section{Co-Morbid Disease in Asthma and COPD}

A number of co-morbidities are commonly reported in populations with severe asthma and COPD (Table 1), and management guidelines advocate the clinical management of these co-morbidities [2, 18]. In COPD, some of these, such as coronary artery disease, heart failure and lung cancer, are strongly associated with mortality, while others, such as hypertension, diabetes, sleep apnoea and reflux, may add to the complexity of managing the disease in individual patients [30].

However, for conditions such as gastro-oesophageal reflux, the evidence that managing these co-morbidities has a major clinical impact on clinical outcome in these conditions is limited [31, 32]. This may be because non- 
Table 1. Common co-morbidities in severe asthma and COPD

\begin{tabular}{|c|c|}
\hline Asthma & COPD \\
\hline $\begin{array}{l}\text { Pulmonary co-morbidities: obstructive sleep apnoea, } \\
\text { hyperventilation syndrome, smoking/smoking-related disease }\end{array}$ & $\begin{array}{l}\text { Pulmonary co-morbidities: obstructive sleep apnoea, } \\
\text { bronchiectasis, interstitial fibrosis }\end{array}$ \\
\hline Obesity and physical deconditioning & Obesity and physical deconditioning \\
\hline $\begin{array}{l}\text { Gastrointestinal co-morbidities: gastro-oesophageal reflux } \\
\text { disease }\end{array}$ & $\begin{array}{l}\text { Gastrointestinal co-morbidities: gastro-oesophageal reflux, } \\
\text { peptic ulcer disease }\end{array}$ \\
\hline $\begin{array}{l}\text { Psychological factors: personality trait, symptom } \\
\text { perception, anxiety, depression }\end{array}$ & $\begin{array}{l}\text { Psychological factors: symptom perception and coping with } \\
\text { breathlessness, anxiety, depression }\end{array}$ \\
\hline $\begin{array}{l}\text { Upper airways: rhinosinusitis/(adults) nasal polyps, vocal cord } \\
\text { dysfunction }\end{array}$ & $\begin{array}{l}\text { Cardiovascular factors: coronary artery disease, congestive heart } \\
\text { failure, atrial fibrillation, hypertension }\end{array}$ \\
\hline $\begin{array}{l}\text { Drug intolerance including aspirin, non-steroidal anti- } \\
\text { inflammatory drugs, } \beta \text {-adrenergic blockers, angiotensin- } \\
\text { converting enzyme inhibitors }\end{array}$ & $\begin{array}{l}\text { Metabolic/systemic factors: hyperglycaemia, underweight, } \\
\text { obesity, osteoporosis }\end{array}$ \\
\hline $\begin{array}{l}\text { Hormonal influences: premenstrual period, menarche, } \\
\text { menopause, thyroid disorders }\end{array}$ & $\begin{array}{l}\text { Oncological factors: lung cancer, oesophageal cancer, pancreatic } \\
\text { cancer }\end{array}$ \\
\hline
\end{tabular}

acid reflux is still occurring or because the presence of gastro-oesophageal reflux has little impact on underlying airways disease; however, it is commonly listed as a cause of chronic cough. Gastro-oesophageal reflux can be effectively surgically treated with fundoplication, and efficacy has been suggested in asthma [33], but until we perform "sham-controlled" studies of fundoplication, it may be difficult to completely unpick the causal relationship between reflux and airways disease. This is in sharp contrast to the evidence for pulmonary rehabilitation in COPD, where the evidence has been consistently positive [34], confirming that intervention for extra-pulmonary morbidity is of value in managing airways disease, and these programmes are evolving to become more patient focussed. A key challenge going forward in managing many of these extra-pulmonary factors will be to tease out association from "cause and effect" and to produce an evidence-based targeting of interventions, to deliver true personalised management.

\section{Heterogeneity in Airways Inflammation in Airways Disease}

Recent data in patients with both mild and severe asthma suggest that there is evidence of significant disease heterogeneity [35-39], and examining gene signatures in well-characterised cohorts of patients with severe asthma has demonstrated that between 25 and $50 \%$ of patients have a prototypic type-2 (T2) cytokine gene signature, socalled "T2-high" disease (with elevated IL-4, -5 and -13 and airway eosinophilia, despite adherence to high-dose corticosteroid treatment). In patients with severe asthma with no evidence of T2 inflammation ("T2-low asthma"), it is likely that their corticosteroid dose has been escalated inappropriately to try to manage persistent symptoms that are not corticosteroid responsive. Given the evidence that corticosteroid responsiveness is confined to T2-high disease $[35,40,41]$, a key challenge for the management of severe asthma in the future is to develop objective tests and validated management algorithms not only to initiate corticosteroid treatment, but also to allow clinicians to determine that additional corticosteroid treatment will not produce any further clinical response. Moving away from the currently advocated symptom-driven escalation of corticosteroid treatment will be a major component of delivering "personalised treatment" in severe asthma in the future and will facilitate optimisation of corticosteroid dose. It would also allow a diagnosis of severe asthma to be made without escalation of corticosteroid treatment past a point where, in many cases, there is unlikely to be any therapeutic benefit.

The same issue of risk versus benefit is apparent regarding the use of ICS in COPD. As discussed above, ICS are usually indicated for exacerbation reduction, and the early clinical trials in COPD did not stratify on the basis of inflammatory phenotype. As a consequence, ICS are prescribed widely in COPD despite little information directing the clinician as to who will really benefit without adverse effects. Recent evidence suggests that the blood eosinophil count may help clinicians in making this decision. In a pooled meta-analysis of 10 trials undertaken by 
GlaxoSmithKline with baseline blood eosinophil count and pneumonia event data available, Pavord et al. [42] calculated the number of pneumonia events stratified by baseline blood eosinophil count $(<2$ and $\geq 2 \%$ of blood leucocytes). They found that patients with lower eosinophil counts at baseline (i.e., <2\%) had a greater risk of developing pneumonia, which was independent of ICS use. Therefore, a low blood eosinophil count may be added to the list of known pre-existing risk factors for pneumonia (age, severe airflow obstruction, co-existent bronchiectasis and previous pneumonia) and may be taken into consideration when deciding to commence inhaled steroid therapy or not. However, starting treatment is quite different from stopping a medicine; any rush to discontinue ICS without careful consideration must be avoided. In a recent post hoc analysis of the Withdrawal of Inhaled Steroids during Optimized Bronchodilator Management (WISDOM) trial, patients with higher baseline blood eosinophil counts $(\geq 4 \%$ or $\geq 300$ cells per $\mu \mathrm{l})$ were significantly more likely to have moderate-to-severe exacerbations after ICS withdrawal [43]. Blood eosinophil count is a relatively easy biomarker to obtain in clinical settings, although the level which accurately distinguishes those patients likely to benefit from those at risk of coming to harm has not been determined. However, further work needs to be done to validate a steroid adjustment strategy based on blood eosinophil count in COPD, including a prospective study withholding inhaled steroids in biomarker-low subjects allied with a precise characterisation of the inflammatory phenotype of exacerbation events.

The above approach is almost certainly an "entry level" approach to inflammatory heterogeneity in airways disease with a characterisation of airways inflammation as either eosinophilic or non-eosinophilic. A key issue which must be addressed in the future is whether this phenotypic heterogeneity in both asthma and COPD can be further sub-divided into discrete mechanistic pathways or endotypes [44]. It is entirely plausible that a number of different biological pathways can give rise to airway eosinophilia, and targeting specific mechanisms is already occurring in asthma with the use of T2 cytokine-specific blockade.

In severe asthma, these new drugs have been targeted in patients with T2-high disease who have refractory eosinophilic asthma despite high-dose ICS. Omalizumab is a recombinant DNA-derived humanised immunoglobulin (Ig) G1K monoclonal antibody that binds selectively to human IgE at the same site as the high-affinity IgE receptor, forming immune complexes with free IgE [45]. This binding inhibits interaction of IgE with IgE recep-

Personalised Medicine for Asthma and COPD tors on the surface of mast cells, basophils and other cell types, preventing the release of inflammatory mediators that occurs in allergic asthma. Clinical trials have demonstrated reduced unscheduled emergency visits and hospital admissions, and current guidelines advocate the use of omalizumab as an add-on therapy in severe asthma [45]. Interestingly, given the lack of efficacy and discontinuation of some other novel anti-IgE therapies (e.g., quilizumab, MEDI-4212 [46]), the observation that some allergic patients with severe asthma do not respond well to omalizumab will potentially allow an exploration of the mechanism of action and a definition of a "responder" on the basis of specific inflammatory pathways.

Therapies targeting IL-5 (mepolizumab, reslizumab) have recently arrived in the clinic and have been shown to half severe exacerbations in subjects with eosinophilic asthma with more modest effects on symptoms and lung function [47, 48]. Therapies targeting the interleukin (IL)-5 receptor (IL-5R) (benralizumab) are also being studied, as well as IL-13 (lebrikizumab, tralokinumab) and IL-4Ra (dupilumab). The recent phase 3 clinical trial programme of the anti-IL-13 therapy lebrikizumab has demonstrated less efficacy than anticipated from phase 2 studies and, whilst disappointing at one level, suggests that the role of IL-13 is not as key in more severe asthma and will almost certainly provide a greater understanding of the role of this cytokine in asthma [49]. There are other strategies targeting the T2 axis, including prostaglandin D2 antagonism [50], and it seems likely that these therapies will all be targeting overlapping patient groups; identifying which patients respond better to different classes of drugs may require "head-to-head" studies, and understanding different responder sub-groups will be a key task when these drugs are all available in the clinic. The intriguing possibility is that of comparative studies allied to a mechanistic evaluation of the drug effect; using predictive biomarkers of clinical response will further enhance our understanding of genotypic variation in asthma.

In COPD, given the evidence that eosinophilic inflammation plays a role in some patients with the disease, therapies targeting the $\mathrm{T} 2$ cytokine axis are being trialled in this population, which is generally stratified using a marker of eosinophilic biology, such as peripheral blood eosinophil count. In a recent placebo-controlled study of benralizumab (an anti-IL-5Ra monoclonal antibody) in patients with moderate-to-severe COPD and eosinophilia, a reduction in acute exacerbations was not seen [51]. However, a reduction in acute exacerbations and small improvements in lung function and quality of life were 
seen in the pre-specified subgroup with baseline eosinophil concentrations of 200 per $\mu$ l or more [51]. It seems likely that the degree of heterogeneity in terms of inflammatory biology is greater in COPD, but understanding the nature and size of the clinical effect of T2 cytokine inhibition in COPD will not only potentially provide a welcome advance in the clinic but go some way to understanding inflammatory heterogeneity in COPD and the other components of the disease which need to be targeted.

Alternative anti-inflammatory strategies in COPD include targeting the imbalance of the airway proteases. Matrix metalloproteases exert tissue-damaging effects in lung disease and are implicated in the development of COPD and in particular the emphysema sub-phenotype. Clearly, inhibiting such action as early as possible is important, and the advent of improved lung imaging may pave its way as a biomarker helping select patients best suited to such treatment $[52,53]$.

\section{Linking Unmet Need and Personalised Treatment in Airways Disease}

Despite the advent of novel anti-T2 cytokine treatments, it is widely recognised that there are likely to remain major unmet needs in airways disease. A major current research focus in asthma is therapeutic management of the T2-low/non-corticosteroid-responsive facets of asthma, particularly in severe disease. It now seems clear that asthma symptoms and altered physiology are manifest in the absence of T2 cytokine/eosinophilic inflammation, but it is unclear what underlying pathophysiological mechanisms drive these processes. Possibilities include a different inflammatory process or non-inflammatory structural problems, such as abnormal smooth muscle contractility, aberrant epithelial signalling or airway infection. Understanding the extent and mechanism of T2low disease in severe asthma will be a major research focus in the next decade.

The role of IL-17 in asthma has generated interest, and an initial study using anti-IL-17 (brodalumab) suggested some efficacy in asthma patients with significant bronchodilator reversibility [54], but the precise role of IL-17 in severe asthma needs to be established. Preliminary data using macrolide therapy in patients with low peripheral blood eosinophil counts have also suggested exacerbation reduction, but whether this is an antibacterial or other anti-inflammatory effect remains to be clarified [55]. Bronchial thermoplasty is now available as a therapeutic intervention in asthma [56], but identifying which individual patients will receive benefit from any of these interventions remains a key challenge. However, optimising corticosteroid treatment and the availability of novel target-specific treatments will provide a great opportunity to both deliver personalised patient-specific treatment and to identify novel mechanisms in severe disease. Novel strategies to optimise corticosteroid dose using composite biomarker approaches are currently being explored in severe asthma, which if successful will be easily transferred to routine clinical care [57].

In COPD, a key area of unmet need is the treatment of those with severe disease that is not likely to respond to conventional medical therapies. In more advanced emphysema, where significant structural and functional damage prevails, there is a need to identify those patients likely to benefit from lung volume reduction surgery (LVRS). In the original National Emphysema Treatment Trial (NETT), it became clear that not all those initially randomised benefitted from LVRS [58]. Sub-groups of responders (upper lobe-predominant emphysema with poor exercise capacity despite pulmonary rehabilitation) were identified highlighting once again the personalised nature of COPD therapy. These findings have helped inform the design of trials of bronchoscopic LVRS involving the placement of one-way endobronchial valves. Recent studies have shown that this treatment may be suitable for those with the more homogeneously distributed emphysema that had experienced such poor outcomes in the NETT trial [59].

The greatest future challenge in airways disease asthma remains a "disease-modifying" therapy. In asthma, it is tempting to speculate that if we could understand why patients with a particular pattern of disease (T2-high/eosinophilic), which is usually responsive to low doses of ICS, become "relatively" corticosteroid resistant and require high-dose (often systemic) treatment, we could target this therapeutically. This area has been the subject of study for many years, but no precise mechanism, as evidenced by a proven therapeutic, has yet emerged. In a randomised controlled withdrawal study of omalizumab (the Evaluating Xolair Persistency of Response after Long-Term Therapy [XPORT] study), 176 patients who had been on omalizumab for at least 5 years were randomised to placebo or continuation of omalizumab [60]. The placebo arm had a shorter time to first exacerbation than those who continued on omalizumab; however, notably, $47.7 \%$ of placebo patients had no exacerbation in a 1 -year follow-up period, and it is interesting to speculate that some patients have a persistent benefit; however, fur- 
ther analysis and studies are required to determine whether this is the case. It is also worth noting that over $25 \%$ of those randomised were not on ICS at the time of randomisation, and it remains unclear whether these data can be extrapolated to patients with severe asthma on omalizumab who frequently require high-dose inhaled steroid treatment in addition to omalizumab to maintain disease control. However, what can be concluded is that, as a group, patients who discontinue omalizumab treatment after long-term use do less well than those who continue treatment.

Disease modification in COPD is perhaps a greater challenge than in asthma for a number of reasons. Firstly, considerably less is known regarding the pathophysiology of COPD, and as a consequence, the development and the use of treatment targeting specific immune pathways have been much slower. Secondly, COPD tends to present in older patients, often when it is well advanced and not perhaps amenable to disease-modifying intervention. Clearly, more work is needed to understand the early life events which contribute to the development of COPD and to improve our ability to identify early disease and within that group select and treat those most likely to suffer rapid lung function decline. Finally, the challenge of avoiding the environmental factors (notably cigarette smoking and burning of biomass fuels) so obviously caus- ative in COPD is enormous [61, 62]. An emerging area of interest is the potential for lung regeneration through the use of mesenchymal stem cells. Despite promising preclinical work in this field, only 1 placebo-controlled clinical trial of systemically administered mesenchymal stem cells in moderate-to-severe COPD has been undertaken [63]. Although apparently safe, there was no anti-inflammatory effect observed and no lung function improvement, suggesting clinical uptake of this mode of treatment in particular for those with more severe disease is some way off.

\section{Conclusion}

Airways disease is heterogeneous, and a "one size fits all" approach to diagnosis and management, whilst delivering benefit at some levels, has also led to differing outcomes in sub-groups of patients due to disease heterogeneity. Precise clinical "personalised" assessment, with a particular focus on understanding the clinical problem, addressing extra-pulmonary morbidity and managing behavioural challenges, such as non-adherence to inhaled steroid treatment, is just as critical to precision medicine in airways disease as targeting the right drug to the right patient.

\section{References}

1 Global Initiative for Asthma: Global strategy for asthma management and prevention. http://ginasthma.org/2016-gina-report-global-strategy-for-asthma-management-andprevention/ (accessed December 20, 2016).

2 Global Initiative for Chronic Obstructive Lung Disease (GOLD): Global strategy for the diagnosis, management and prevention of COPD. 2016. http://goldcopd.org/.

- 3 Serra-Batlles J, Plaza V, Morejón E, Comella A, Brugués J: Costs of asthma according to the degree of severity. Eur Respir J 1998;12:13221326.

4 Foo J, Landis SH, Maskell J, Oh YM, van der Molen T, Han MK, Mannino DM, Ichinose $\mathrm{M}$, Punekar Y: Continuing to confront COPD international patient survey: economic impact of COPD in 12 countries. PLoS One 2016;11:e0152618.

5 Hekking PP, Wener RR, Amelink M, et al: The prevalence of severe refractory asthma. J Allergy Clin Immunol 2015;135:896-902.

-6 Kessler R, Partridge MR, Miravitlles M, Cazzola M, Vogelmeier C, Leynaud D, et al: Symptom variability in patients with severe COPD: a pan-European cross-sectional study. Eur Respir J 2011;37:264-272.
7 Burgel PR, Wedzicha JA: Chronic cough in chronic obstructive pulmonary disease: time for listening? Am J Respir Crit Care Med 2013;187:902-904.

8 Polley L, Yaman N, Heaney L, Cardwell C, Murtagh E, Ramsey J, Macmahon J, Costello RW, McGarvey L: Impact of cough across different chronic respiratory diseases: comparison of two cough-specific health-related quality of life questionnaires. Chest 2008;134:295302.

-9 Calverley PM: Cough in chronic obstructive pulmonary disease: is it important and what are the effects of treatment? Cough 2013;9:17.

10 Jones PW, Harding G, Berry P, Wiklund I, Chen WH, Kline Leidy N: Development and first validation of the COPD Assessment Test. Eur Respir J 2009;34:648-654.

11 Leidy NK, Murray LT, Monz BU, Nelsen L, Goldman M, Jones PW, Dansie EJ, Sethi S: Measuring respiratory symptoms of COPD: performance of the EXACT-Respiratory Symptoms Tool (E-RS) in three clinical trials. Respir Res 2014;15:124.

12 Heaney LG, Robinson DS: Severe asthma treatment: need for characterising patients. Lancet 2005;365:974-976.
13 Heaney LG, Conway E, Kelly C, Johnston BT, English C, Stevenson M, Gamble J: Predictors of therapy resistant asthma: outcome of a systematic evaluation protocol. Thorax 2003; 58 : 561-566.

14 Cleutjens F, Triest F, Wilke S, Vanfleteren LE, Franssen FM, Janssen DJ, Rutten EP, Spruit MA, Wouters EF: New insights in chronic obstructive pulmonary disease and comorbidity. Am J Respir Crit Care Med 2015;191:1081.

15 Agusti A, Bel E, Thomas M, et al: Treatable traits: toward precision medicine of chronic airway diseases. Eur Respir J 2016;47:410419.

16 Gonem S, Raj V, Wardlaw AJ, Pavord ID, Green R, Siddiqui S: Phenotyping airways disease: an A to E approach. Clin Exp Allergy 2012;42:1664-1683.

17 Abdulqawi R, Dockry R, Holt K, Layton G, McCarthy BG, Ford AP, Smith JA: P2X3 receptor antagonist (AF-219) in refractory chronic cough: a randomised, double-blind, placebo-controlled phase 2 study. Lancet 2015;385:1198-1205. 
18 Chung KF, Wenzel SE, Brozek JL, et al: International ERS/ATS guidelines on definition, evaluation and treatment of severe asthma. Eur Respir J 2014;43:343-373.

19 Flynn RW, MacDonald TM, Hapca A, MacKenzie IS, Schembri S: Quantifying the real life risk profile of inhaled corticosteroids in COPD by record linkage analysis. Respir Res 2014; 15:141.

20 Calverley PM, Anderson JA, Celli B, et al: Salmeterol and fluticasone propionate and survival in chronic obstructive pulmonary disease. N Engl J Med 2007;356:775-789.

$\checkmark 21$ Wedzicha JA, Banerji D, Chapman KR, Vestbo J, Roche N, Ayers RT, Thach C, Fogel R, Patalano F, Vogelmeier CF; FLAME Investigators: Indacaterol-glycopyrronium versus salmeterol-fluticasone for COPD. N Engl J Med 2016;374:2222-2234.

22 Brown HM: Treatment of chronic asthma with prednisolone: significance of eosinophils in the sputum. Lancet 1958;2:1245-1247.

-23 Gamble J, Stevenson M, McClean E, Heaney LG: The prevalence of non-adherence in difficult asthma. Am J Respir Crit Care Med 2009;180:817-822.

-24 Murphy AC, Proeschal A, Brightling CE, et al: The relationship between clinical outcomes and medication adherence in difficult-tocontrol asthma. Thorax 2012;67:751-753.

-25 McNicholl DM, Stevenson M, McGarvey LP, Heaney LG: The utility of fractional exhaled nitric oxide suppression in the identification of nonadherence in difficult asthma. Am J Respir Crit Care Med 2012;186:1102-1108.

-26 Blackstock FC, ZuWallack R, Nici L, Lareau SC: Why don't our patients with chronic obstructive pulmonary disease listen to us? The enigma of nonadherence. Ann Am Thorac Soc 2016;13:317-323.

-27 Press VG, Arora VM, Shah LM, Lewis SL, Ivy K, Charbeneau J, Badlani S, Nareckas E, Mazurek A, Krishnan JA: Misuse of respiratory inhalers in hospitalized patients with asthma or COPD. J Gen Intern Med 2011;26:635642.

28 Sulaiman I, Cushen B, Greene G, Seheult J, Seow D, Rawat F, MacHale E, Mokoka M, Moran CN, Sartini Bhreathnach A, MacHale P, Tappuni S, Deering B, Jackson M, McCarthy H, Mellon L, Doyle F, Boland F, Reilly RB, Costello RW: Objective assessment of adherence to inhalers by COPD patients. Am J Respir Crit Care Med 2016, Epub ahead of print.

29 Nieuwlaat R, Wilczynski N, Navarro T, et al: Interventions for enhancing medication adherence. Cochrane Database Syst Rev 2014; 11:1-730.

30 Divo M, Cote C, de Torres JP, Casanova C, Marin JM, Pinto-Plata V, Zulueta J, Cabrera C, Zagaceta J, Hunninghake G, Celli B; BODE Collaborative Group: Comorbidities and risk of mortality in patients with chronic obstructive pulmonary disease. Am J Respir Crit Care Med 2012;186:155-161.
31 Gibson PG, Henry RL, Coughlan JL: Gastrooesophageal reflux treatment for asthma in adults and children. Cochrane Database Syst Rev 2003;2:1-33.

32 Ingebrigtsen TS, Marott JL, Vestbo J, Nordestgaard BG, Hallas J, Lange P: Gastroesophageal reflux disease and exacerbations in chronic obstructive pulmonary disease. Respirology 2015;20:101-107.

33 Rothenberg SS, Bratton D: The effects of laparoscopic Nissen fundoplication to enhance pulmonary function in the treatment of a patient with severe asthma and gastroesophageal reflux disease. J Allergy Clin Immunol 2008;121:1069-1070.

- 34 Lacasse Y, Martin S, Lasserson TJ, Goldstein RS: Meta-analysis of respiratory rehabilitation in chronic obstructive pulmonary disease. A Cochrane systematic review. Eura Medicophys 2007;43:475-485.

35 Woodruff PG, Modreck B, Choy DF, et al: Thelper type 2-driven inflammation defines major subphenotypes of asthma. Am J Respir Crit Care Med 2009;180:388-395.

36 Jia G, Erickson RW, Choy DF, et al: Periostin is a systemic bio-marker of eosinophilic air way inflammation in asthmatic patients. J Allergy Clin Immunol 2012;130:647-654.

37 Butler CA, McQuaid S, Taggart CC, et al: Glucocorticoid receptor $\beta$ and histone deacetylase 1 and 2 expression in the airways of severe asthma. Thorax 2012;67:392-398.

38 Shikotra A, Choy DF, Ohri CM, et al: Increased expression of immunoreactive thymic stromal lymphopoietin in patients with severe asthma. J Allergy Clin Immunol 2012; 129:104-111.

39 Choy D, Shikotra A, Siddiqui S, et al: Mutually exclusive Th2 and Th17 bronchial gene expression signatures are associated with eosinophilia in asthma. Eur Respir J 2014; 44(suppl 58):P3868.

40 McGrath KW, Icitovic N, Boushey HA, et al: A large subgroup of mild-to-moderate asthma is persistently non-eosinophilic. Am J Respir Crit Care Med 2012;185:612-619.

41 Pavord ID, Brightling CE, Woltmann G, Wardlaw AJ: Non-eosinophilic corticosteroid unresponsive asthma. Lancet 1999;353;22132214.

42 Pavord ID, Lettis S, Anzueto A, Barnes N: Blood eosinophil count and pneumonia risk in patients with chronic obstructive pulmonary disease: a patient-level meta-analysis. Lancet Respir Med 2016;4:731-741.

43 Watz H, Tetzlaff K, Wouters EF, Kirsten A, Magnussen H, Rodriguez-Roisin R, Vogelmeier C, Fabbri LM, Chanez P, Dahl R, Disse B, Finnigan H, Calverley PM: Blood eosinophil count and exacerbations in severe chronic obstructive pulmonary disease after withdrawal of inhaled corticosteroids: a post-hoc analysis of the WISDOM trial. Lancet Respir Med 2016;4:390-398.

44 Ray A, Oriss TB, Wenzel SE: Emerging molecular phenotypes of asthma. Am J Physiol Lung Cell Mol Physiol 2015;308:L130-L140.
45 Rodrigo GJ, Neffen H, Castro-Rodriguez JA: Efficacy and safety of subcutaneous omalizumab vs placebo as add-on therapy to corticosteroids for children and adults with asthma: a systematic review. Chest 2011;139:2835.

46 Harris JM, Maciuca R, Bradley MS, Cabanski CR, Scheerens H, Lim J, Cai F, Kishnani M, Liao XC, Samineni D, Zhu R, Cochran C, Soong W, Diaz JD, Perin P, Tsukayama M, Dimov D, Agache I, Kelsen SG: A randomized trial of the efficacy and safety of quilizumab in adults with inadequately controlled allergic asthma. Respir Res 2016;17:29.

-47 Ortega HG, Liu MC, Pavord ID, Brusselle GG, FitzGerald JM, Chetta A, Humbert M, Katz LE, Keene ON, Yancey SW, Chanez P; MENSA Investigators: Mepolizumab treatment in patients with severe eosinophilic asthma. N Engl J Med 2014;371:1198-1207.

48 Bjermer L, Lemiere C, Maspero J, Weiss S, Zangrilli J, Germinaro M: Reslizumab for inadequately controlled asthma with elevated blood eosinophil levels: a randomized phase 3 study. Chest 2016;150:789-798.

49 Hanania NA, Korenblat P, Chapman KR, Bateman ED, Kopecky P, Paggiaro P, Yokoyama A, Olsson J, Gray S, Holweg CT, Eisner M, Asare C, Fischer SK, Peng K, Putnam WS, Matthews JG: Efficacy and safety of lebrikizumab in patients with uncontrolled asthma (LAVOLTA I and LAVOLTA II): replicate, phase 3, randomised, double-blind, placebocontrolled trials. Lancet Respir Med 2016;4: 781-796.

50 Gonem S, Berair R, Singapuri A, Hartley R, Laurencin MF, Bacher G, Holzhauer B, Bourne M, Mistry V, Pavord ID, Mansur AH, Wardlaw AJ, Siddiqui SH, Kay RA, Brightling CE: Fevipiprant, a prostaglandin D2 receptor 2 antagonist, in patients with persistent eosinophilic asthma: a single-centre, randomised, double-blind, parallel-group, placebo-controlled trial. Lancet Respir Med 2016; 4:699-707.

-51 Brightling CE, Bleecker ER, Panettieri RA Jr, Bafadhel M, She D, Ward CK, Xu X, Birrell C, van der Merwe R: Benralizumab for chronic obstructive pulmonary disease and sputum eosinophilia: a randomised, double-blind, placebo-controlled, phase $2 \mathrm{a}$ study. Lancet Respir Med 2014;2:891-901.

52 Cho MH, Castaldi PJ, Hersh CP, Hobbs BD, Barr RG, Tal-Singer R, Bakke P, Gulsvik A, San José Estépar R, Van Beek EJ, Coxson HO, Lynch DA, Washko GR, Laird NM, Crapo JD, Beaty TH, Silverman EK; NETT Genetics, ECLIPSE, and COPDGene Investigators: A genome-wide association study of emphysema and airway quantitative imaging phenotypes. Am J Respir Crit Care Med 2015;192: 559-569. 
53 Ostridge K, Williams N, Kim V, Bennett M, Harden S, Welch L, Bourne S, Coombs NA, Elkington PT, Staples KJ, Wilkinson TM: Relationship between pulmonary matrix metalloproteinases and quantitative CT markers of small airways disease and emphysema in COPD. Thorax 2016;71:126-132.

54 Busse WW, Holgate S, Kerwin E, et al: Randomized, double-blind, placebo-controlled study of brodalumab, a human anti-IL-17 receptor monoclonal antibody, in moderate to severe asthma. Am J Respir Crit Care Med 2013;188:1294-1302.

55 Brusselle GG, Joos G: Is there a role for macrolides in severe asthma? Curr Opin Pulm Med 2014;20:95-102.

56 Castro M, Rubin AS, Laviolette M, et al: Effectiveness and safety of bronchial thermoplasty in the treatment of severe asthma: a multicenter, randomized, double-blind, sham-controlled clinical trial. Am J Respir Crit Care Med 2010;181:116-124.
57 Medical Research Council Refractory Asthma Stratification Programme in the United Kingdom (RASP-UK): Moving away from the "one size fits all" approach to treatment in severe asthma. www.rasp.org.uk/ (accessed September 1, 2016).

58 Martinez FJ, Foster G, Curtis JL, Criner G, Weinmann G, Fishman A, DeCamp MM, Benditt J, Sciurba F, Make B, Mohsenifar Z, Diaz P, Hoffman E, Wise R; NETT Research Group: Predictors of mortality in patients with emphysema and severe airflow obstruction. Am J Respir Crit Care Med 2006;173: 1326-1334.

59 Valipour A, Slebos DJ, Herth F, Darwiche K, Wagner M, Ficker JH, Petermann C, Hubner RH, Stanzel F, Eberhardt R; IMPACT-StudyTeam: Endobronchial valve therapy in patients with homogeneous emphysema: results from the IMPACT study. Am J Respir Crit Care Med 2016;194:1073-1082.
60 Busse WW, Trzaskoma B, Omachi TA, et al: Evaluating Xolair persistency of response after long-term therapy (XPORT). Am J Respir Crit Care Med 2014;189:A6576.

61 Bilano V, Gilmour S, Moffiet T, d'Espaignet ET, Stevens GA, Commar A, Tuyl F, Hudson I, Shibuya K: Global trends and projections for tobacco use, 1990-2025: an analysis of smoking indicators from the WHO Comprehensive Information Systems for Tobacco Control. Lancet 2015;385:966-976.

62 Gordon SB, Bruce NG, Grigg J, Hibberd PL, Kurmi OP, Lam KB, Mortimer K, Asante KP, Balakrishnan K, Balmes J, Bar-Zeev N, Bates MN, Breysse PN, Buist S, Chen Z, Havens D, Jack D, Jindal S, Kan H, Mehta S, Moschovis P, Naeher L, Patel A, Perez-Padilla R, Pope D, Rylance J, Semple S, Martin WJ 2nd: Respiratory risks from household air pollution in low and middle income countries. Lancet Respir Med 2014;2:823-860.

63 Weiss DJ, Casaburi R, Flannery R, LeRouxWilliams M, Tashkin DP: A placebo-controlled, randomized trial of mesenchymal stem cells in COPD. Chest 2013;143:15901598. 